\title{
The Present Situation and Existing Issues of Monographs Grammar Study of Excavated Documents -- Taking Pronouns Study as an Example
}

\author{
Yan-mei ZHANG ${ }^{1,2, a,{ }^{*}}$ and Han DING ${ }^{1, b}$ \\ ${ }^{1}$ School of Foreign Language, Guilin University of Electronic Technology, \\ Guilin, China \\ ${ }^{2}$ College of Liberal Arts, South China Normal University, Guangzhou, China \\ a576720717@qq.com, b34098482@qq.com
}

\begin{abstract}
Keywords: Excavated documents, Monographs grammar study, Pronouns study, Present situation, Existing problem.
\end{abstract}

\begin{abstract}
The passage takes an example of pronouns study, discussing the present situation and existing problems of monographs grammar study of excavated documents. It points out that there are mainly three questions lying in monographs grammar study of excavated documents currently. Initially, there is not enough exhaustive statistics but examples and not enough vertical and horizontal comparison. Secondly, it focuses on description so that explanation and thereotical thinking are insufficient. Thirdly, no one shows any interest in many monographs grammar study of excavated documents. The essay indicates that it is a good era at present for working on monographs grammar study of excavated documents and Chinese philologists and linguists on excavated documents can completely make a great career in this aspect.
\end{abstract}

\section{Introduction}

Chinese linguists used to talkabout the importance of monographs grammar study and the difficulty of working on monographs grammar study with countless times.

For instance, Mr. Bojun Yang said in the preface of Study on Function Word in Zuo Zhuan that in ancient and medieval period documents, it is necessary to make study on monographs and special topics and comparative study integrating some aspects. These studies, regardless of the thickness of monographs, the width of special topics and the size of comparison range, are hard to be demanded to gain substantial information, fine analysis and truly reflected objective grammar phenomenon as well as grasp its characteristics to make reliable conclusion.

As another example, Mr. Xiliang Guo considers that Chinese grammar history needs to be established on monographs grammar study and periodical grammar study. He once said in the Preface of Ancient Chinese Monographs Grammar Stuty that monographs grammar study is a systematic project, so we should fully recognize it has huge difficulty, for the reason that it generally goes on on the basis of completing monographs index and dictionary. The purpose of monographs grammar study is to do comprehensive descriptions on grammars of one particular monograph. Although the research could be done separately, every part of it is related to the entirety. It should not only do exhaustive research but also coordinate with each other. Studying verbs in a monograph could not solve problems only by focusing on its verbs and it is virtually possible to refer to all word classes. It should also be seen that solutions of many issues are not only by a monograph but need to study other works in the same era and may even trace up and down and expand the coverage. Thus, any flirty style and 
impatient thinking is going to cause problems.

Most of previous ancient Chinese monographs grammar studies focused on transmitted documents while less took excavated documents monographs grammar studies as objects. There are mainly three reasons. Firstly, ancient Chinese characters and excavated document materials are hard to tackle so that quite a few scholars studying ancient Chinese do not pay attention to or have no ability to utilize research achievements of ancient Chinese and excavated documents. In the next place, many scholars studying ancient Chinese do not always obtain very clear language conceptions and very deep grammar study accomplishments. Thirdly, in experts studying Chinese history, only few of them notice information like using ancient Chinese characters and excavated documents. Some experts hope to utilize ancient Chinese characters and excavated document materials, but on account of the limitations of a variety of conditions, there are many confinements exsiting in mastering, using and comprehending ancient Chinese characters and excavated document materials. Therefore, even though previous scholars have done plenty of works on using ancient Chinese characters and excavated document information, the aspect of excavated document monograph grammar study still has a long way to go in total.

The passage takes an example of pronouns study, discussing the present situation and existing problems of monographs grammar study of excavated documents.

\section{The Present Situation of Monographs Grammar Study of Excavated Documents -- Taking Pronouns Study as an Example}

Pronoun is an important word class of language. Before Ma Shi Wen Ton, the first systematic work about Chinese grammar was born, there were ancient Chinese scholars doing research on Chinese pronouns. After MaShi Wen Ton was written, plenty of scholars do research on Chinese pronouns. It can be seen that with plenty of underground materials discovered, pronouns study on excavated documents have begun to attract the attention of scholars. Predecessors have done many related research achievements in this area and provided a foundation to further research.

However, previous studies also have obvious limitations. Currently, a majority of publications referring to pronouns study of excavated documents are monograph grammar research and quite a few introduce pronouns in grammar study as pronoun is one part of it. Therefore, it is impossible to do deeper discussion on pronouns. For instance, there are publications like The Grammar Study of The Oracle-bone Inscriptions of Yin Ruins by Xiechu Guan (Language Institute of Chinese Academy of Sciences, 1953), Oracle Syntax by Yujin Zhang (Xuelin Press, 2001), Research on Classic Words of Oracle-Bone Inscriptions of Yin Ruins by Fengbin Yang (Huacheng Press, 2003), Inscriptions Grammar of Yin Ruins by Xi Li (Shanxi Normal University Press,2004); Study on Function Words on Inscriptions on Bronzes of Western Zhou by Huarong Liang (doctoral dissertation of Sichuan University, 2005), Study on Classic Words on Inscriptions on Bronzes of Zhou Dynasty (Function Words Part) by Zhenyu $\mathrm{Wu}$ (doctoral dissertation of Jilin University, 2006) and Chinese Characters study on inscriptions on bronzes of the Warring States by Cuicui Liu (master thesis of East China Normal University, 2010); The Grammar Study of Shuihudi Qin Tomb Bamboo Slips by Desheng Wei (Capital Normal UniversityPress, 2000), Grammar Study of Bamboo Slips in the Chu Dynasty of the Warring States by Mingxiao Li (Wuhan University Press, 2010), The Vocabulary Study of Baoshan Chu Slips by Ying Wang 
(Xiamen University Press, 2008), Language Study of Baoshan Chu Slips by Bo Liu (master thesis of Beijing Normal University, 2005), Grammar Study of Guodian Chu Slips by Yuemin Deng (doctoral dissertation of Sichuan University, 2006), Vocabulary Study of Shuihudi Qin Tomb Bamboo Slips by Hong Yang (master thesis of East China Normal University, 2008), Grammar Study of Longgang Qin Bamboo Slips by Changhua Xiong (master thesis of Southwestern University, 2010) and Vocabulary Systematic Study of Fangmatan by Huiye Bao (master thesis of East China Normal University, 2013).

Publications above all introduce pronouns in grammar study. As pronoun is just a very small part of it, the publications do not concerntrate on pronouns of excavated documents monographs to study. For instance, The Grammar Study of Shuihudi Qin Tomb Bamboo Slips (Desheng Wei, 2000) which has been discussed above is a book comprehensively describing the grammatical problems with Shuihudi Qin tomb bamboo slips as the study subject. Chapter 2 of the book is number, addressing and pronoun - pronoun is just a small part of it. The whole book, The Vocabulary Study of Baoshan Chu Slips (Ying Wang, 2004), contains eleven chapters, and pronoun, chapter six, analyzing the meaning and usage of nine pronouns of Baoshan Chu Slips - pronoun is also just a small part of it.

It is rarely few for completely regarding excavated document pronouns as research targets, with only The First Pronouns Study of Bamboo Slips in Qin Dynasty (master thesis of South China Normal University, 2005) and The First Pronouns Study of Excavated Documents in Pre-Qin Times written by Jingwen Liu (master thesis of South China Normal University, 2003). However, since these two master theses include many excavated document corpora instead of doing exhaustive and deep discussions on pronouns of a monograph of excavated document, these are not monographs researching pronouns in the strict sense.

At present, research achievements of monographs grammar study of excavated document in the strict sense are few with only few single passages. For example, The First Pronouns Study on 'Bamboo Slips in Tsinghua University' (Part One) (Language Characters Study on Bambooslips and Silks (The Six Series), 205-222 pp) written by Yujiao Wang, Primary Studies on the Usage and Times of 'jue' and 'qi' in 'Bamboo Slips in Tsinghua University' (Part One)' (Language Characters Study on Bambooslips and Silks (The Six Series), 223-238 pp) written by $\mathrm{Ye} \mathrm{Li} \mathrm{and} \mathrm{The}$ Amount and Syntactic Functions of the First Person Pronoun 'wu' of The bamboo slips of Chu State in the Warring States Period collected by the Shanghai Museum -and Consult with Grammar Study of The bamboo slips of Chu State in the Warring States by Mingxiao Li. ('The First Session Ancient Chinese Characters and Language Research of Excavated Documents International Symposium' Conference Collected Papers, December 2016).

\section{The Existing Issues of Monographs Grammar Study of Excavated Documents - Taking Pronouns Study as an Example}

We make a combing to publications on monographs grammar study of excavated document (pronouns are part of it) and research achievements of monographs grammar study of excavated document in the strict sense (only few single passages). Then, we discover the mainly existing issues of monographs grammar study of excavated documents. 


\section{There is not Enough Exhaustive Statistics but Examples and not Enough Vertical and Horizontal Comparison.}

Initially, there is not enough exhaustive statistics but examples. It mainly shows in publications on monographs grammar study of excavated document (pronouns are part of it) and most of them limit in properties of making examples. However, research achievements of monographs grammar study of excavated document in the strict sense (only few single passages) basically make exhaustive statistics to pronouns discussed in passages with concrete data and deep analysis.

Mr. Leshi He said in Several Understanding to Monographs Grammar Study (Zhenjiang College Journals, first periodical in 1999) that monographs grammar study is the foundation stone of Chinese history research. Chinese history research must discover features of Chinese in every era, summing up the inner rules of Chinese development. Thus, monograph research to representative works of every era becomes an essential guarantee to build skyscrapers of Chinese history. Also, he considered that the most important feature of monograph grammar study is that do exhaustive investigations to all corpora and does not allow 'misappropriation' issue but rather make all issues known to the public. Thus, from the point of doing exhaustive investigations to all corpora, monographs grammar study of excavated document needs further improvement.

Secondly, there is not enough vertical and horizontal comparison. Studying pronouns refer to other word classes. For instance, some words have both pronoun and other usages. For another example, it should not only study bamboo slips of Chu but bamboo slips of Qin (or it should not only study Bao Mountain bamboo slips of Chu, Guo Dian bamboo slips of Chu, but also study Shuihudi bamboo slips of Qin as well as exhaustively add up characters of bamboo slips, characters of silks and jade text) so as to comprehensively mirror the status and relevant relations of pronouns in a monograph in the whole Warring States period when studying pronouns in characters of bamboo slips. Meanwhile, it is possible to make relationship with oracles and bronze inscriptions of Western Zhou Dynasty and the Spring and Autumn in order to understand the position of it in the whole Chinese pronoun history development and more clearly to know its origin and development. In total, concerning the pronouns study of monographs grammar study of excavated documents, some aspects like the vertical and horizontal comparison need to be strengthened.

\section{It Focuses on Description So that Explanation and Thereotical Thinking are Insufficient}

First of all, it focuses on description and lacks explanation. The issue exists both in monographs grammar study of excavated document (pronouns are part of it) and research achievements of monographs grammar study of excavated document in the strict sense (only few single passages), especially in the former.

Noam Chomsky once pinpointed that collections and classifications of actual corpora are lower stages of grammatical analysis. It must include highly abstract summary when going to an advanced stage while the final purpose of grammar study is to put forward reasonable explanations to language phenomenon and discuss the working mechanism of the brain from the language faculty furtherly as well as understand the essence of thinking activities of human beings. Thus, it is researching monographs grammar study of excavated document that not only require the sufficiency of exploration and description but also require the sufficiency of explanation. Taking pronoun as an example, apart from exhaustive descriptions, it should be done to find reasonable explanations of pronoun phenomenon of excavated 
documents and trace the rules and causes of occurring behind the pronoun phenomenon by hook or by crook.

In the next place, thereotical thinking is insufficient. Many monographs grammar study of excavated document (pronouns are part of it) and research achievements of monographs grammar study of excavated document in the strict sense (only few single passages) just describe by showing respect to language facts. Furtherly, they just try to make explanations, few of them grasping research target from a strategic height from theories. Moreover, few of them study contemporary word classes' theories like Syntactic categorytheoryfor reference, descriptive grammar study theory, the three-plane grammar theory and theory of cognitive linguistics to do descriptions and explanations of pronouns system of monographs grammar study of excavated document.

\section{No one Shows Any Interest in Many Monographs Grammar Study of Excavated Documents}

Currently, there is a limitation to monographs grammar study of excavated documents and that is no one shows any interest in many monographs grammar study of excavated documents. Taking pronouns study asan example, even though there have been some achievements in pronouns study of excavated documents of the Warring States and Qin Dynasty, domestic China have announced quite abundant corpora of excavated documents of the Warring States and Qin Dynasty now actually, including bronze script of the Warring States, scripts from bamboo slips of the Warring States (including Wulipai bamboo slips of Chu, Angtian Lake bamboo slips of Chu, Yang Jia Wan bamboo slips of Chu, Xinyang bamboo slips of Chu, Wang Mountain bamboo slips of Chu, Tomb of Marquis Yi of Zeng bamboo slips, Jiu Dian bamboo slips of Chu, Bao Mountain bamboo slips of Chu, Guo Dian bamboo slips of Chu, Shanghai Museum bamboo slips of Chu, Xincai bamboo slips of Chu, Xincai Geling bamboo slips of Chu, bamboo slips in The Chinese University of Hong Kong, Tian Xing Guan bamboo slips of Chu, bamboo slips of Chu in Tsinghua University, Shuihudi bamboo slips of Qin, Shuihudi bamboo tablets of Qin, Qingchuan bamboo tablets of Qin, Fangma Beach bamboo slips of Qin, Yue Shan bamboo tablets of Qin, Longgang bamboo slips of Qin, Choujiatai bamboo slips of Qin, Liyebamboo slips of Qin and Yuelu Academy bamboo slips of Qin), book copied on silk of the Warring States (like book copied on silk of the Warring States in Changsha bullet Library) and jade text of the Warring States (including Yin jade marginal inscription of Qin, Xing Qi jade inscription, jade Huang admonitions carved on a stone, Shou Qiu lithoglyph, ten Qin kingdom inscribed steles and the engravings on Mount Yi). Relevant researches relating to pronouns of excavated documents of the Warring States and Qin Dynasty in the past were too far to reach the feelers to all these precious corpora. Few theses and dissertations have begun to determine the selected topic of this area but far from ideal. No one shows any interest in many summarizations of pronouns systems of document monographs in these precious corpora and further researches.

\section{Conclusion}

The passage takes an example of pronouns study, discussing the present situation and existing problems of monographs grammar study of excavated documents. It points out that there are mainly three questions lying in monographs grammar study of excavated documents currently. Initially, there is not enough exhaustive statistics but examples and not enough vertical and horizontal comparison. Secondly, it focuses on 
description so that explanation and thereotical thinking are insufficient. Thirdly, no one shows any interest in many monographs grammar study of excavated documents.

In fact, as a tree is judged by its fruit, other monographs grammar study of excavated documents of word classes and grammatical issues also exist similar problems.

In recent 100 years, oracles, inscriptions on bronzes and characters on bambooslips and silks have unearthed in a large quantity, of which are oracles with characters, bronze wares with inscriptions, bamboo slips and other piecemeal materials excavated underground. They have huge quantities and according to researching language, especially studying ancient Chinese, it is very abundant materials to study its pronunciaiton, word, grammar and characters.

Compared with transmitted documents, excavated documents have advantages of clear time and region, keeping the original appearance of language and no spread error. It can be said that it is a good era at present for working on monographs grammar study of excavated documents and Chinese philologists and linguists on excavated documents can completely make a great career in this aspect.

In brief, it will obtain very significant academic value for using excavated documents so as to establish more historical authentic ancient Chinese grammar history and vocabulary history when it comes to attaching importance to utilizing excavated document materials, vigorously promoting ancient Chinese monographs grammar study from the aspect of ancient Chinese characters and excavated documents, making reasonable explanations on the basis of exhaustive statistics and analyses and grasping research target from a strategic height of monographs grammar study of excavated document from theories. Moreover, experts should learn from research theories of language at home and abroad, using progressive theory methods to guide research practices.

\section{Acknowledgement}

The article got advice from Mr. Yujin Zhang, the professor and doctoral supervisor of College of Liberal Arts, South China Normal University. It was also supported by the Project of National Social Science Foundation in 2013, with the project index number 13BYY106, in which the content was 'content words study of excavated documents of the Warring States and lexicography'. Thanks again.

\section{References}

[1] Yujin Zhang,A Research on Function Words in Excavated Materials of the Warring States, People press, Beijing, 2011.

[2] Yanmei Zhang, The Amount and Syntactic Functions of the First Person Pronoun 'wu' of The bamboo slips of Chu State in the Warring States Period collected by the Shanghai Museum --and Consult with Grammar Study of The bamboo slips of Chu State in the Warring States by Mingxiao Li,'The First Session Ancient Chinese Characters and Language Research of Excavated Documents International Symposium' Conference Collected Papers, December 2016.

[3] Yanmei Zhang,etal,The Retrospect and the Prospect of a Research on Pronouns in Excavated Materials of the Warring States, 2016 International Conference on Contemporary Education, Social Sciences and Humanities (ICCESSH 2016), 
St.Petersburg, Russia, Sept.27-28,2016. Atlantis Press, Electronic product, Paris, France, pp. 447-450.

[4] Yanmei Zhang and Han DING, Pronouns Study in China-Taking a Research on Pronouns in Excavated Materials of Pre-Qin Dynasty as an Example, 2016 3rd InternationalConferenceonEducation, Language,Artand Inter-cultural Communication (ICELAIC 2016) , Xiamen, Fujian, China, December 2-4, 2016. Atlantis Press, Electronic product, Paris,France, pp. 360-363.

[5] Leshi He, Study on Function Words of Zuo Zhuan (Revised Version), second ed., The Commercial Press, Beijing, December 2004.

[6] Leshi He, Several Understanding to Monographs Grammar Study, Zhenjiang College Journals, first periodical, 1999. 